\title{
Produção de feijão caupi em função da salinidade e regulador de crescimento
}

\author{
Francisco de A. de Oliveira ${ }^{1}$, José F. de Medeiros ${ }^{1}$, Rita de C. Alves ${ }^{2}$, \\ Luan A. Lima ${ }^{1}$, Sandy T. dos Santos ${ }^{1} \&$ Lúcia R. de L. Régis ${ }^{1}$ \\ ${ }^{1}$ Departamento de Ciências Ambientais e Tecnológicas/Universidade Federal Rural do Semi-Árido. Mossoró, RN. E-mail: thikaoamigao@ufersa.edu.br \\ (Autor correspondente); jfmedeir@ufersa.edu.br; luanefa2@yahoo.com.br; sandy_thomaz@hotmail.com; luregina13@hotmail.com \\ ${ }^{2}$ Faculdade de Ciências Agrárias e Veterinárias/Universidade Estadual Paulista “Júlio de Mesquita Filho”. Jaboticabal, SP. E-mail: cassiaagro-24@outlook.com
}

\section{Palavras-chave:}

Vigna unguiculata (L.) Walp. estresse salino

fitorreguladores

\begin{abstract}
R E S U M O
O uso eficiente de água salina depende da tolerância da cultura e da adoção de tecnologia que reduzam o efeito da salinidade. O trabalho foi desenvolvido em Mossoró-RN, para avaliar o uso do bioestimulante Stimulate e da salinidade na cultura do feijão caupi. O delineamento experimental utilizado foi o inteiramente casualizado em esquema fatorial $4 \times 4$, sendo quatro concentrações salinas na água de irrigação $\left(0,5 ; 2,0 ; 3,5\right.$ e $\left.5,0 \mathrm{dS} \mathrm{m}^{-1}\right)$ e quatro de bioestimulante aplicadas através de pulverização $\left(0 ; 0,5 ; 1,0\right.$ e $\left.1,5 \mathrm{~L} \mathrm{ha}^{-1}\right)$, com quatro repetições. Foram analisadas as seguintes variáveis: número de vagens por planta, comprimento das vagens, número de grãos por vagem, produção de grãos e índice de colheita. A análise estatística dos dados revelou que houve interação significativa entre os fatores para a maioria das variáveis. O uso de concentrações elevadas de bioestimulante potencializou o efeito deletério da salinidade da mesma forma como o uso de água com alta salinidade inibiu o efeito do bioestimulante no rendimento da cultura. $\mathrm{O}$ uso do bioestimulante Stimulate com concentrações de 0,5 a $0,75 \mathrm{~L} \mathrm{ha}^{-1}$ proporcionou aumento na produção de grãos de feijão caupi desde que a irrigação tenha sido realizada com água de condutividade elétrica menor que $3,5 \mathrm{dS} \mathrm{m}^{-1}$.
\end{abstract}

\section{Key words:}

Vigna unguiculata (L.) Walp. salt stress plant regulators

\section{Production of cowpea crop under salinity and growth regulator}

\begin{abstract}
A B S T R A C T
The efficient use of saline water depends on the tolerance of crop and technology adoption to reduce the effect of salinity. The present study was conducted with the objective to evaluate the use of the growth promoter Stimulate on cowpea plants under saline conditions. The experimental design was completely randomized, in a $4 \times 4$ arrangement, composed of four levels of salinity of irrigation water $\left(0.5,2.0,3.5\right.$ and $\left.5.0 \mathrm{dS} \mathrm{m}^{-1}\right)$ and four levels of Stimulate $\left(0,0.5,1.0\right.$ and $\left.1.5 \mathrm{~L} \mathrm{ha}^{-1}\right)$, with four replications. The following variables were analysed: number of pods plant ${ }^{-1}$, pod length, number of grains pod $^{-1}$, grain yield and harvest index. Statistical analysis of the data revealed that there was significant interaction between the factors for most variables. The use of high concentrations of growth promoter enhances the deleterious effects of salinity, as well as the use of irrigation water of high salinity inhibits the beneficial effect of plant growth regulator in crop yield. The use of biostimulant Stimulate with concentrations of 0.5 to $0.75 \mathrm{~L} \mathrm{ha}^{-1}$ provides an increase in grain yield of cowpea, provided that irrigation is performed with water of electrical conductivity less than $3.5 \mathrm{dS} \mathrm{m}^{-1}$.
\end{abstract}




\section{INTRODUÇÃO}

O feijão caupi (Vigna unguiculata (L.) Walp.) é uma das leguminosas mais consumidas no Norte e Nordeste do Brasil, representando importante fonte de proteína, energia, fibras e minerais, além de gerar emprego e renda. Apesar de ser uma cultura bastante comum na região Nordeste é, nesta área, que são registrados os menores rendimentos da cultura. No estado do Rio Grande do Norte, por exemplo, na safra 20132014, a produtividade média foi de apenas $555 \mathrm{~kg} \mathrm{ha}^{-1}$, com uma estimativa de apenas $353 \mathrm{~kg} \mathrm{ha}^{-1}$ para a safra 2014-2015 (CONAB, 2015).

Como forma de elevar a produtividade da cultura, baixar os custos de produção e elevar a renda do produtor rural, é fundamental a adoção de tecnologias, tais como: o manejo adequado da irrigação e da adubação, entre outras.

Estudos já desenvolvidos com a cultura do feijão caupi em regime de irrigação têm demonstrado o potencial produtivo da cultura. Oliveira et al. (2011) obtiveram, trabalhando com níveis de irrigação (273; 257; 241 e $187 \mathrm{~mm}$ ) produtividade máxima de $1.420,51 \mathrm{~kg} \mathrm{ha}^{-1}$ de grãos, com a lâmina de 257,2 $\mathrm{mm}$. Silva \& Neves (2011), observaram, trabalhando com 20 genótipos de feijão caupi em condições de sequeiro e irrigado, produtividade média de grãos variando de 658,2 a $1.070,3 \mathrm{~kg}$ $\mathrm{ha}^{-1}$ para o cultivo de sequeiro e de 982,0 a $1.831,9 \mathrm{~kg} \mathrm{ha}^{-1}$ no cultivo irrigado demonstrando, assim, o potencial produtivo da cultura em regime de irrigação; no entanto, além do adequado suprimento hídrico para as plantas, outro aspecto de grande importância está relacionado com a qualidade da água utilizada na irrigação, principalmente quanto à concentração de sais dissolvidos (Medeiros et al., 2003).

O feijão caupi é considerado uma espécie moderadamente tolerante à salinidade da água de irrigação apresentando salinidade limiar de 3,3 $\mathrm{dS} \mathrm{m}^{-1}$ (Ayers \& Westcot, 1999). Apesar disto, pesquisas têm demonstrado que a elevação da salinidade do solo decorrente da irrigação com água salina pode inibir o desenvolvimento das plantas em consequência de alterações nos parâmetros fisiológicos, de crescimento e de rendimento da cultura (Bezerra et al., 2010; Silva et al., 2013). Em estudo desenvolvido por Furtado et al. (2014) com a cultura do feijão caupi sob condições de salinidade, os autores observaram que a salinidade do solo provocou retardamento da floração e elevou a taxa de abortamento de flores de forma proporcional ao aumento da salinidade.

Um dos principais desafios de pesquisadores e produtores é o uso de água salina na irrigação cujo êxito está relacionado ao manejo adequado da irrigação e na adoção de outras tecnologias que possibilitem aumentar a tolerância das plantas à salinidade, de modo que a cultura atinja a produtividade esperada e boa qualidade dos seus produtos sem proporcionar riscos mínimos de salinização para os solos (Medeiros et al., 2007).

O emprego de fitorreguladores como técnica agronômica para otimizar a produção em diversas culturas tem crescido nos últimos anos. Bioestimulantes vegetais são combinações de diferentes biorreguladores ou de biorreguladores e outras substâncias que, aplicadas exogenamente, possuem ações similares aos grupos de hormônios vegetais conhecidos (Castro \& Vieira, 2001).
A aplicação foliar de bioestimulante no feijoeiro comum (P. vulgaris) proporcionou incrementos na nodulação, no crescimento radicular, no conteúdo de açúcares solúveis e aminoácidos totais e na atividade do nitrato redutase (Almeida et al., 2014).

$\mathrm{Na}$ literatura são escassas as pesquisas com o bioestimulante Stimulate na cultura do feijão caupi mas já foram desenvolvidos estudos com outras espécies da mesma família botânica. Para a cultura da soja a aplicação de bioestimulante proporcionou incremento no número de vagens, no número de grãos e na produção por planta (Klahold et al., 2006; Bertolin et al., 2010). Para a cultura do feijoeiro comum (Phaseolus vulgaris), Abrantes et al. (2011) observaram que a aplicação de Stimulate aumentou o número de grãos por planta e a produtividade em duas cultivares de feijoeiro no estádio reprodutivo.

Apesar dos benefícios do uso de regulador de crescimento na produção de grãos ainda são necessários mais estudos para várias culturas e em diferentes condições ambientais, principalmente com plantas cultivadas sob condições de estresse (Oliveira et al., 2013), sendo esta a principal justificativa da pesquisa. Ante o exposto este trabalho foi desenvolvido com o objetivo de avaliar a eficácia do uso de bioestimulante na cultura do feijão caupi sob condições de salinidade.

\section{Material e Métodos}

O experimento foi realizado nos meses janeiro a março de 2014 em casa de vegetação localizada na área experimental do Departamento de Ciências Ambientais e Tecnológicas da Universidade Federal Rural do Semi-Árido (UFERSA), em Mossoró, RN, Brasil (5 11' $31^{\prime \prime}$ ' $; 37^{\circ} 20^{\prime} 40^{\prime \prime} \mathrm{W}$; altitude de $18 \mathrm{~m}$ ).

A casa de vegetação utilizada apresenta cobertura de polietileno de baixa densidade transparente, com $0,10 \mathrm{~mm}$ de espessura, tratada contra a ação de raios ultravioleta e em formato tipo arco, com 7,0 m de largura e $21 \mathrm{~m}$ de comprimento. As paredes laterais e frontais são confeccionadas com telas antiafídeos e rodapé de $0,30 \mathrm{~m}$ em concreto armado.

Durante o período experimental foram realizados o monitoramento de temperatura e umidade relativa do ar no interior da casa-de-vegetação utilizando-se termo-higrômetro digital (Mod. 30.5000.02, TFA Technology HK) instalado no centro da casa-de-vegetação a uma altura de $1,5 \mathrm{~m}$. Neste período foram registradas as seguintes variações de temperatura e umidade relativa do ar no interior da casa-devegetação: 22,1 a $31,9^{\circ} \mathrm{C}$ para Tmin; 31,1 a $37,2^{\circ} \mathrm{C}$ para Tmed; 36,9 a $45,4{ }^{\circ} \mathrm{C}$ para Tmax; 12 a $34 \%$ para URmin; 29 a $55 \%$ para URmed; e 44 a $77 \%$ para URmax.

Material de solo classificado como Argissolo Vermelho Amarelo (EMBRAPA, 2006) foi utilizado e coletado na camada de $0-20 \mathrm{~cm}$ de profundidade, em área não cultivada, localizada no Campus da UFERSA. O material coletado foi secado ao ar e posteriormente peneirado em malha de $2,0 \mathrm{~mm}$ e analisado quimicamente (EMBRAPA, 1997); os resultados estão apresentados na Tabela 1.

O delineamento estatístico utilizado foi o inteiramente casualizados, com os tratamentos arranjados em esquema fatorial $4 \times 4$ com quatro repetições. Os tratamentos resultaram da combinação de quatro concentrações de sal na água de 
Tabela 1. Características físicas e químicas do solo utilizado no experimento

\begin{tabular}{|c|c|c|c|c|c|c|c|c|c|c|c|c|c|c|c|c|}
\hline \multicolumn{9}{|c|}{ Características químicas } & \multicolumn{8}{|c|}{ Características físicas } \\
\hline \multirow{2}{*}{$\mathrm{pH}$} & \multirow{2}{*}{$\begin{array}{l}\text { M.0. } \\
\text { (\%) }\end{array}$} & \multirow{2}{*}{$\begin{array}{c}P \\
\left(\mathrm{mg} \mathrm{dm}^{-3}\right)\end{array}$} & $\mathbf{K}^{+}$ & $\mathrm{Na}^{+}$ & $\mathrm{Ca}^{+2}$ & $\mathrm{Mg}^{+2}$ & $\mathrm{Al}^{+3}$ & $\mathrm{H}^{+}$ & \multicolumn{3}{|c|}{ Fração granulométrica $\left(\mathrm{g} \mathrm{kg}^{-1}\right)$} & \multirow{2}{*}{$\begin{array}{l}\text { Classe } \\
\text { textural }\end{array}$} & \multicolumn{2}{|c|}{ Umidade $\left(\mathrm{g} \mathrm{g}^{-1}\right)$} & \multicolumn{2}{|c|}{ Densidade $\left(\mathrm{kg} \mathrm{dm}^{-3}\right.$} \\
\hline & & & & & (cmol & $\left.\mathrm{dm}^{-3}\right)$ & & & Areia & Silte & Argila & & CC & PMP & Ds & Dp \\
\hline 5,7 & 1,05 & 2,20 & 0,14 & 0,13 & 0,40 & 0,60 & 0,25 & 3,05 & 707,2 & 172,2 & 120,6 & FA & 0,15 & 0,06 & 1,53 & 2,68 \\
\hline
\end{tabular}

FA - Franco Arenoso; CC - Capacidade de campo para $\psi_{\mathrm{m}}=-10 \mathrm{kPa}$; PMP - Ponto de murcha permanente para $\psi_{\mathrm{m}}=-1500 \mathrm{kPa}$; Ds - Densidade do solo ou aparente; DP - Densidade de partículas

irrigação (que resultaram nas seguintes condutividades elétricas: $S_{1}-0,5 ; S_{2}-2,0 ; S_{3}-3,5$ e $S_{4}-5,0 \mathrm{dS} \mathrm{m}^{-1}$ ) com quatro concentrações de bioestimulante $\left(\mathrm{B}_{1}-0 ; \mathrm{B}_{2}-0,5 ; \mathrm{B}_{3}-1,0\right.$ e $\mathrm{B}_{4}-1,5$ $\mathrm{L} \mathrm{ha}^{-1}$ ). Cada unidade experimental foi representada por um vaso plástico com capacidade para $25 \mathrm{~kg}$ de solo, contendo duas plantas.

A semeadura foi realizada no dia 11 de janeiro de 2014 colocando-se, em cada vaso, cinco sementes de feijão caupi (Vigna unguiculata (L.) Walp), cv. Carnaubais; aos cinco dias após a emergência foi realizado o desbaste deixando-se duas plantas por vaso; após o desbaste foram iniciados os tratamentos referentes ao manejo de irrigação com águas salinas.

Para a salinidade $S_{1}\left(0,5 \mathrm{dS} \mathrm{m}^{-1}\right)$ foi utilizada água proveniente de poço profundo localizado no Campus central da UFERSA; para obtenção da água dos demais níveis salinos $\left(\mathrm{S}_{2}, \mathrm{~S}_{3}\right.$ e $\left.\mathrm{S}_{4}\right)$, foi adicionada, à água de menor salinidade $\left(\mathrm{S}_{1}\right)$, uma mistura de sais de $\mathrm{NaCl}, \mathrm{CaCl}_{2} \cdot 2 \mathrm{H}_{2} \mathrm{O}$ e $\mathrm{MgCl}_{2} \cdot 6 \mathrm{H}_{2} \mathrm{O}$ mantendo-se a proporção equivalente de 7:2:1, obedecendo a relação entre condutividade elétrica da água de irrigação e sua concentração $\left(\mathrm{mmol}_{\mathrm{c}} \mathrm{L}^{-1}=\mathrm{CE}_{\mathrm{a}}\right.$ $\times 10)$, conforme Rhoades et al. (2000).

Para cada condutividade elétrica utilizou-se um sistema de irrigação composto por um reservatório de PVC (310 L), uma eletrobomba de circulação Metalcorte/Eberle, autoventilada, modelo EBD250076, linhas laterais de $12 \mathrm{~mm}$ e emissores do tipo microtubos, com vazão média de $2,5 \mathrm{~L} \mathrm{~h}^{-1}$.

O bioestimulante utilizado no ensaio foi o Stimulate, um produto líquido composto por três reguladores vegetais contendo $90 \mathrm{mg} \mathrm{L}^{-1}(0,009 \%)$ de cinetina, $50 \mathrm{mg} \mathrm{L}^{-1}(0,005 \%)$ de ácido giberélico, $50 \mathrm{mg} \mathrm{L}^{-1}(0,005 \%)$ de ácido indolbutírico e 99,981\% de ingredientes inertes (Castro \& Vieira, 2001).

A aplicação de bioestimulante foi realizada pela manhã iniciando-se às $8 \mathrm{~h} 00 \mathrm{~min}$, em uma única vez, quando as plantas se apresentavam em pleno florescimento (40 dias após a semeadura). As pulverizações foram realizadas aplicando-se o regulador vegetal em toda a parte aérea da planta até o completo molhamento das folhas utilizando-se um pulverizador manual com capacidade de $5 \mathrm{~L}$ e se aplicando volume de calda equivalente a $300 \mathrm{~L} \mathrm{ha}^{-1}$ (Abrantes et al., 2011). Para os tratamentos sem aplicação de bioestimulante as plantas foram pulverizadas apenas com água aplicando-se o mesmo volume de calda dos demais tratamentos.

Todas as aplicações foram realizadas no período da manhã utilizando-se o mesmo pulverizador, com um bico cônico, tendo-se o cuidado de realizar a tríplice lavagem após a aplicação de cada concentração.

A colheita foi realizada no dia 26 de março de 2014 (74 dias após a semeadura), quando as vagens estavam secas e foram avaliadas as seguintes variáveis: número de vagens por planta (NVP); comprimento médio de vagem (CMV) comprimento, em $\mathrm{cm}$, de cinco vagens tiradas ao acaso de cada parcela; número de grãos por vagem (NGV) - contagem obtida da média de cinco vagens tiradas ao acaso; produção de grãos (PROD) - determinada pela produção total de grãos em cada planta, em g planta ${ }^{-1}$. Determinou-se ainda o índice de grãos (IG) a partir da relação entre a massa seca de vagens e de grãos, utilizando-se a Eq. 1; utilizou-se amostragem de cinco vagens por vaso.

$$
\mathrm{IG}=\left(\frac{\mathrm{MG}}{\mathrm{MV}}\right) \times 100
$$

em que:

IG - índice de grãos, \%;

MG - massa de grãos coletados em cinco vargens, g; e

MV - massa total de cinco vagens, g.

Os dados obtidos foram analisados estatisticamente pelo teste $\mathrm{F}$ desdobrando-se as análises sempre que a interação se mostrou significativa. As variáveis que apresentaram resposta significativa foram analisadas estatisticamente por meio de análise de regressão.

\section{Resultados e Discussão}

A análise de variância mostrou que houve interação entre os fatores salinidade da água de irrigação e bioestimulante sobre as variáveis número de vagens por planta (NVP), número de grãos por vagem (NGV) e produção de grãos (PROD) em níveis de 0,01 de significância, não ocorrendo efeito significativo da interação entre os fatores para comprimento médio de vagem $(\mathrm{CMV})$ e índice de grãos (IG) $(\mathrm{p}>0,05)$. Quanto ao efeito isolado dos fatores, com exceção do IG, a salinidade da água de irrigação afetou significativamente todas as variáveis analisadas, com significância em nível de 0,01 , para NVP, NGV e PROD, bem como de 0,05 de probabilidade para CMV. Em relação ao efeito isolado do bioestimulante ocorreram respostas significativas em nível de $\mathrm{P}<0,01$ de significância para NVP e PROD, além de IG em nível de 0,05 de significância (Tabela 2).

Tabela 2. Resumo da análise de variância para número de vagens por planta (NVP), comprimento médio de vagem (CMV), número de grãos vagem ${ }^{-1}$ (NGV), produção de grãos planta $^{-1}$ (PRPD) e índice de grãos (IG) de feijão caupi em função da aplicação foliar de bioestimulante e irrigação com água salina

\begin{tabular}{|c|c|c|c|c|c|}
\hline \multirow{2}{*}{$\begin{array}{c}\text { Fonte } \\
\text { de variação }\end{array}$} & \multicolumn{5}{|c|}{ Quadrados médios } \\
\hline & NVP & CMV & NGV & PROD & IG \\
\hline Salinidade (S) & 93,21 ** & $25,84^{*}$ & 25,60 ** & $98,13^{* *}$ & $16,14^{\text {ns }}$ \\
\hline Bioestimulante (B) & $16,54^{* *}$ & $3,65^{\text {ns }}$ & $2,73^{\text {ns }}$ & $17,31^{* *}$ & 85,39 * \\
\hline Interação (S x B) & $7,16^{\star *}$ & $7,09^{\text {ns }}$ & $8,14^{* *}$ & $16,31^{* *}$ & $26,15^{\mathrm{ns}}$ \\
\hline Resíduo & 7,16 & 3,98 & 2,29 & 1,38 & 25,37 \\
\hline C.V. (\%) & 16,27 & 12,11 & 16,93 & 16,13 & 6,54 \\
\hline
\end{tabular}
significativo 
Na Figura 1A são mostrados os resultados obtidos para o número de vagens por plantas (NVP) em função do aumento da salinidade da água de irrigação em plantas pulverizadas com bioestimulante. Nas concentrações de 0,0; 0,5 e 1,0 L ha-1 (B1, B2 e B3, respectivamente) houve resposta quadrática ao aumento da salinidade, com maiores valores ocorrendo nas condutividades elétricas de 2,1; 1,4 e 2,2 $\mathrm{dS} \mathrm{m}^{-1}$, com 6,5; 7,0 e 9,7 vagens por planta, para B1, B2 e B3, respectivamente.

Para a concentração B4 $\left(1,5 \mathrm{~L} \mathrm{ha}^{-1}\right)$ verificou-se que o aumento na salinidade da água resultou em redução linear de 1,1 vagens por planta a cada incremento unitário de condutividade elétrica de forma que o maior valor (7,4 vagens por planta) ocorreu nas plantas irrigadas com água de $0,5 \mathrm{dS} \mathrm{m}^{-1}$ (Figura 1A).

Fazendo uma análise geral da Figura $1 \mathrm{~A}$ percebeu-se que a aplicação de bioestimulante com a maior concentração $\left(1,5 \mathrm{~L} \mathrm{ha}^{-1}\right)$ aumentou o efeito da salinidade sobre esta variável. Constatouse, ainda na Figura 1, que o uso de água de maior salinidade $\left(5,0 \mathrm{dS} \mathrm{m}^{-1}\right)$ provocou os menores valores, independentemente das concentrações de bioestimulante e, ao comparar com os resultados obtidos sob a menor salinidade, houve redução total de 76, 65, 69 e 67\%, para B1, B2, B3 e B4, respectivamente.

Redução no NVP do feijão caupi em resposta à salinidade também foi observada por Assis Júnior et al. (2007) e Bezerra et al. (2010). De acordo com Furtado et al. (2014), o estresse salino provoca redução na emissão de ramos reprodutivos, além de aumentar a taxa de abortamento.

Com relação ao efeito da aplicação de bioestimulante sobre nas plantas irrigadas com águas de salinidade 0,5;2,0 e 3,5 dS $\mathrm{m}^{-1}$. Não houve resposta significativa ao bioestimulante nas plantas irrigadas com água de maior salinidade $\left(5,0 \mathrm{dS} \mathrm{m}^{-1}\right)$, obtendo-se NVP médio de 2,3 (Figura 1B).

Para as plantas irrigadas com água de menor salinidade $(0,5$ $\mathrm{dS} \mathrm{m}^{-1}$ ), o incremento nas concentrações de bioestimulante resultou em aumento linear no número de vagens por planta de forma que o maior valor foi obtido na concentração de 1,5 $\mathrm{L} \mathrm{ha}^{-1}$ (7,5 vagens por planta), correspondendo ao aumento de

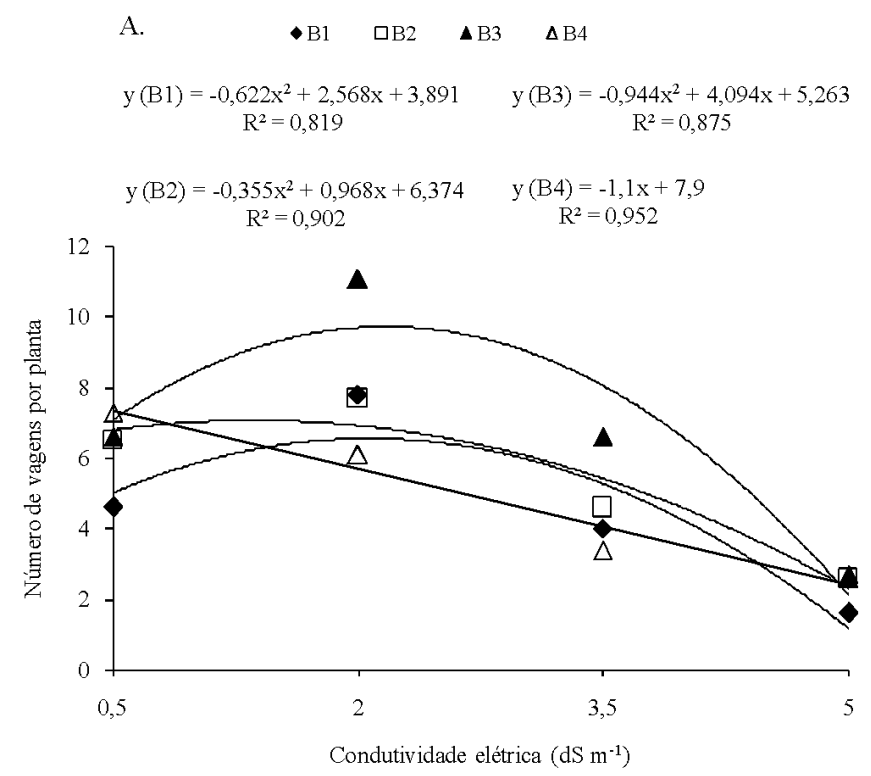
o NVP, verificaram-se respostas significativas ao bioestimulante

$49 \%$ em relação à ausência de bioestimulante (5,0 vagens por planta) (Figura 1B).

Para as condutividades elétricas de 2,0 e 3,5 dS m-1, verificaram-se respostas quadráticas às concentrações de bioestimulante, com maiores valores de NVP ocorrendo nas concentrações de 0,67 e $0,73 \mathrm{~L} \mathrm{ha}^{-1}$, com 10,1 e 6,4 vagens por planta, respectivamente (Figura $1 \mathrm{~B}$ ).

Na literatura são encontrados resultados divergentes sobre o efeito do uso de Stimulate no NVP. Em trabalho desenvolvido com feijoeiro comum (Phaseolus vulgaris L.), Dourado Neto et al. (2014) não observaram efeito deste regulador vegetal sobre o número de vagens por planta, embora Abrantes et al. (2011) tenham verificado resposta linear e positiva do uso desse regulador de crescimento sobre essa variável, com maior NVP obtido para a concentração de 2,0 $\mathrm{L} \mathrm{ha}^{-1}$.

Para o comprimento médio de vagem (CMV), houve resposta significativa apenas para o fator salinidade da água de irrigação, com dados apresentando melhor ajuste à equação quadrática; o maior valor de CMV ocorreu na salinidade de $1,25 \mathrm{dS} \mathrm{m}^{-1}(17,5 \mathrm{~cm})$ apresentando decréscimo a partir deste nível salino (Figura 2). No entanto, pode-se observar, na Figura 2, que houve pouca variação no CMV entre as condutividades elétricas de 0,5 a $3,5 \mathrm{dS} \mathrm{m}^{-1}$ de forma que a maior variação foi observada entre os níveis 3,5 e 5,0 dS $\mathrm{m}^{-1}$, apresentando redução de $11 \%$ entre esses níveis (Figura 2).

Na Figura 3A são apresentados os resultados obtidos para número de grãos por vagem (NGV) em função da salinidade da água de irrigação em plantas tratadas com bioestimulante. Verificou-se que a resposta da cultura à salinidade variou de acordo com as concentrações de bioestimulante.

Quando as plantas foram pulverizadas com bioestimulante nas concentrações B1 $\left(0 \mathrm{~L} \mathrm{ha}^{-1}\right)$ e B4 $\left(1,5 \mathrm{~L} \mathrm{ha}^{-1}\right)$, ocorreram respostas quadráticas com maiores valores na salinidade de 2,5 dS m$~ m^{-1}$, para ambas as concentrações, obtendo-se valores máximos de 10 grãos por vagem correspondendo ao aumento de $22 \%$ em comparação com os valores obtidos na menor salinidade (Figura 3A).

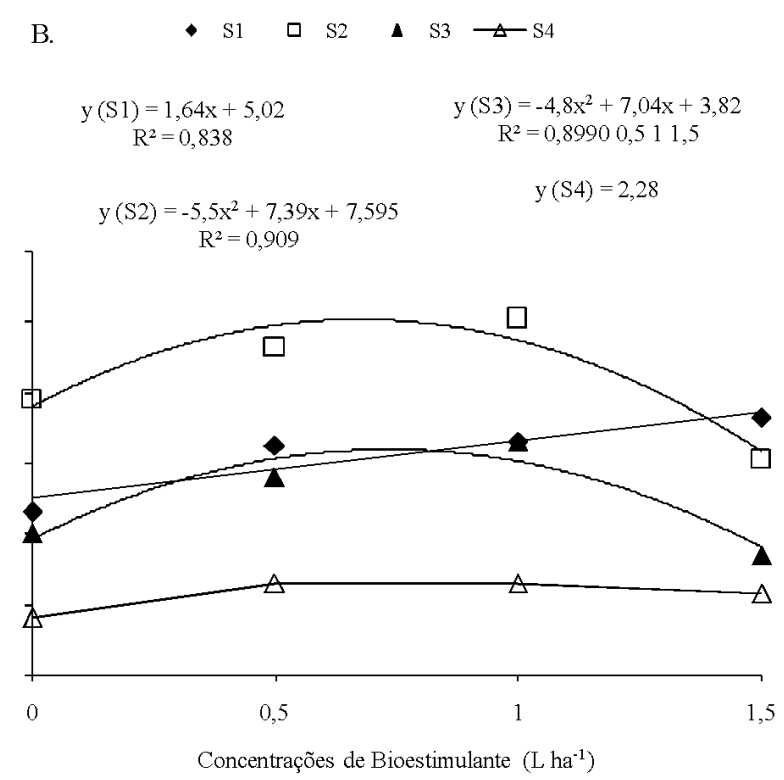

Figura 1. Número de vagens por planta em feijão caupi sob irrigação com águas salinas (A) e concentrações de bioestimulante (B) (B1-0; B2-0,5; B3-1,0 e B4-1,5 L ha-1 de bioestimulante; S1-0,5; S2-2,0; S3-3,5 e S4-5,0 dS m-1) 
Figura 2. Comprimento de vagem em feijão caupi sob irrigação com águas salinas

Para a concentração B2 $\left(0,5 \mathrm{~L} \mathrm{ha}^{-1}\right)$, foi observada resposta linear e decrescente de forma que ocorreu redução de 1,38 grãos por aumento unitário da condutividade elétrica da água de irrigação resultando em redução total de $49,2 \%$ na maior salinidade $\left(5,0 \mathrm{dS} \mathrm{m}^{-1}\right)$, na qual se obteve valor de NGV mínimo de 6 grãos por vagem. Não houve efeito da salinidade quando se utilizou a concentração de $1,0 \mathrm{~L} \mathrm{ha}^{-1}$ (B3) obtendo-se valor médio de aproximadamente 9 grãos vagem ${ }^{-1}$ (Figura 3A).

Em trabalho desenvolvido por Assis Júnior et al. (2007) não foi observado efeito da salinidade sobre o NGV; em irrigadas com água salina apresentaram reduções lineares nesta variável com perdas de 1,46 grão por vagem por aumento unitário da condutividade elétrica, resposta próximo à obtida neste trabalho para a concentração B2.

Com relação ao efeito das concentrações de bioestimulante sobre o NGV ocorreram respostas quadráticas nas plantas irrigadas com águas de condutividades elétricas de 0,5 e 2,0

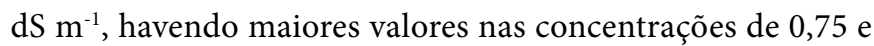
$0,61 \mathrm{~L} \mathrm{ha}^{-1}$ de bioestimulante, com NGV máximos de 11,6 e 10,9, respectivamente (Figura 3B).

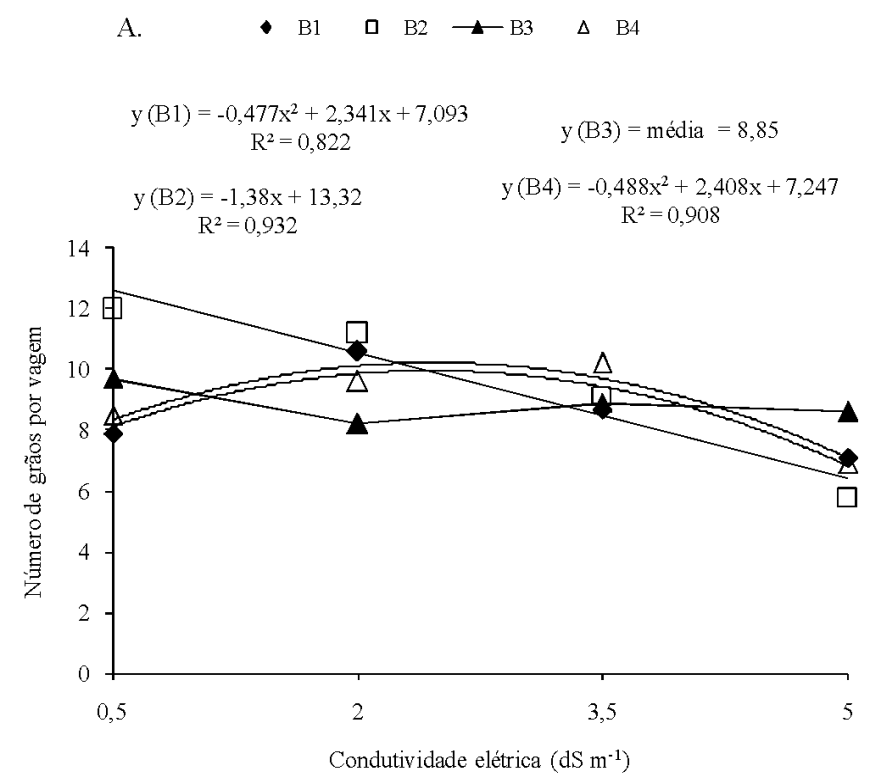

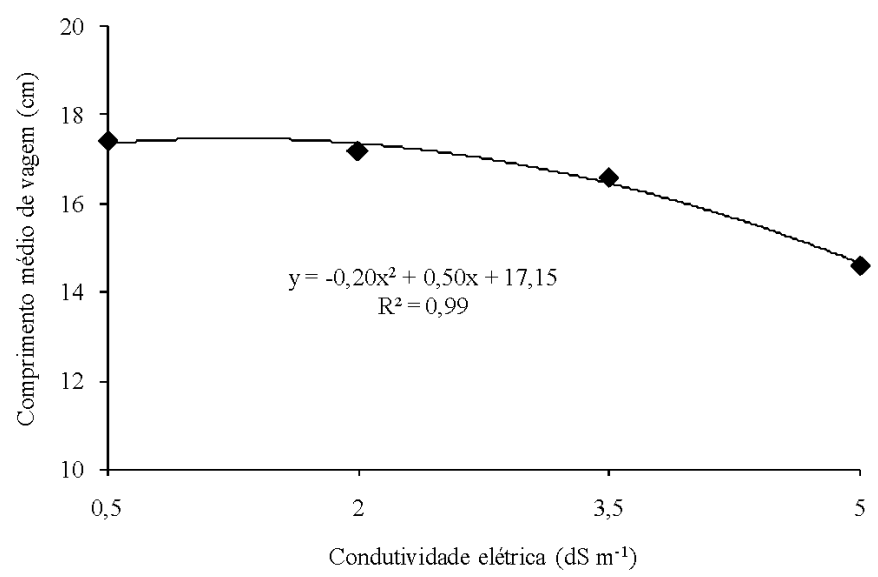
contrapartida, Furtado et al. (2014) verificaram que plantas

Para a condutividade elétrica de $3,5 \mathrm{dS} \mathrm{m} \mathrm{m}^{-1}$, o aumento unitário nas concentrações de bioestimulante resultou em aumento linear 1,2 grãos por vagem de forma que o maior NGV ocorreu na concentração de $1,5 \mathrm{~L} \mathrm{ha}^{-1}$ (10,0 grãos por vagem). Observou-se ainda que, apesar de ter havido resposta positiva, o maior valor obtido na concentração B4 $\left(1,5 \mathrm{~L} \mathrm{ha}^{-1}\right)$ foi menor, em termos absolutos, aos valores obtidos nas condutividades de 0,5 e 2,0 dS m $\mathrm{m}^{-1}$ ou seja, para se obter vagens com número de grãos semelhantes aos obtido nas menores salinidades, foi necessário aplicar maior concentração de bioestimulante. Em concentrações elevadas de sal na água de irrigação $\left(5,0 \mathrm{dS} \mathrm{m}^{-1}\right)$, não houve efeito do bioestimulante, obtendo-se NGV médio de 7,28 grãos por vagem; assim, percebeu-se que o efeito do bioestimulante foi inibido completamente pelo estresse salino (Figura 3B).

O efeito do bioestimulante sobre o número de grãos por vagem também foi observado por Dourado Neto et al. (2014) trabalhando com o feijoeiro comum (Phaseolus vulgaris). Em contrapartida, Abrantes et al. (2011) e Almeida et al. (2014) não obtiveram respostas significativas do feijoeiro comum $(P$. vulgaris) à aplicação de bioestimulante para a mencionada variável. Semelhantemente, Bertolin et al. (2010) não verificaram respostas significativas na cultura da soja (Glycine $\max ($ L.) Merrill).

As divergências observadas entre esses autores e os resultados obtidos neste trabalho demonstram que o efeito do bioestimulante Stimulate sobre o número de grãos por vagem pode variar de acordo com a cultura e as condições ambientais.

Com relação à produção de grãos (PROD), os resultados demonstraram que houve efeito quadrático da salinidade independentemente das concentrações de bioestimulante, com maiores valores ocorrendo nas condutividades elétricas de 2,0; 1,$8 ; 2,8$ e 1,8 dS m$~^{-1}$, com produções máximas de 7,3; 10,1; 9,4 e 1,9 g por planta, para B1, B2, B3 e B4, respectivamente (Figura 4A).

$\mathrm{O}$ aumento parcial da produção em resposta à salinidade ocorreu em virtude da tolerância da cultura à salinidade

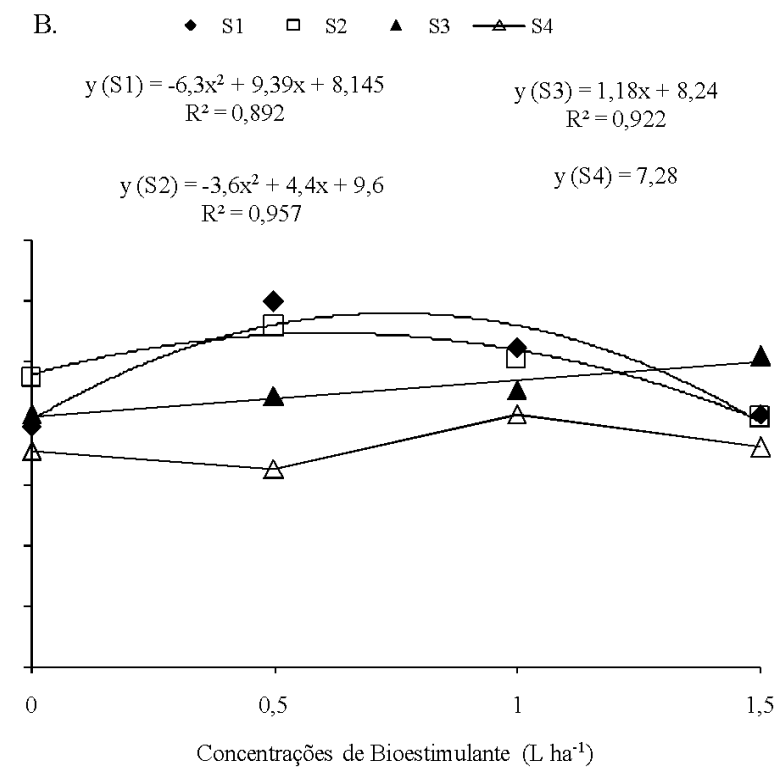

Figura 3. Número de grãos vagem ${ }^{-1}$ em feijão caupi sob irrigação com águas salinas (A) e concentrações de bioestimulante (A) (B1-0; B2-0,5; B3-1,0 e B4-1,5 L ha-1 de bioestimulante; S1-0,5; S2-2,0; S3-3,5 e S4-5,0 dS m $)$ 

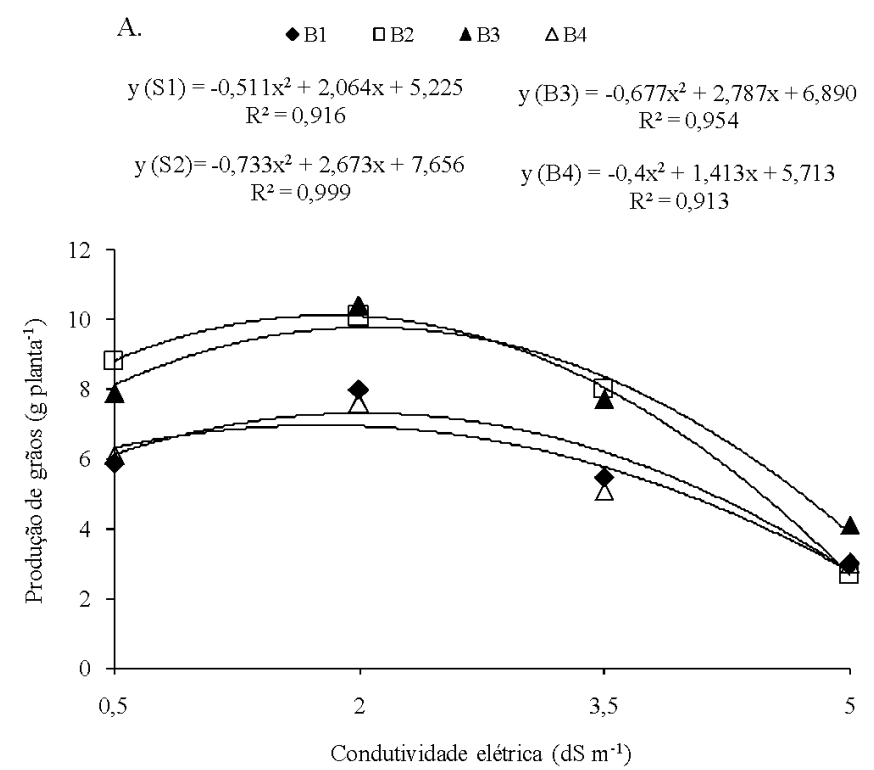

B.
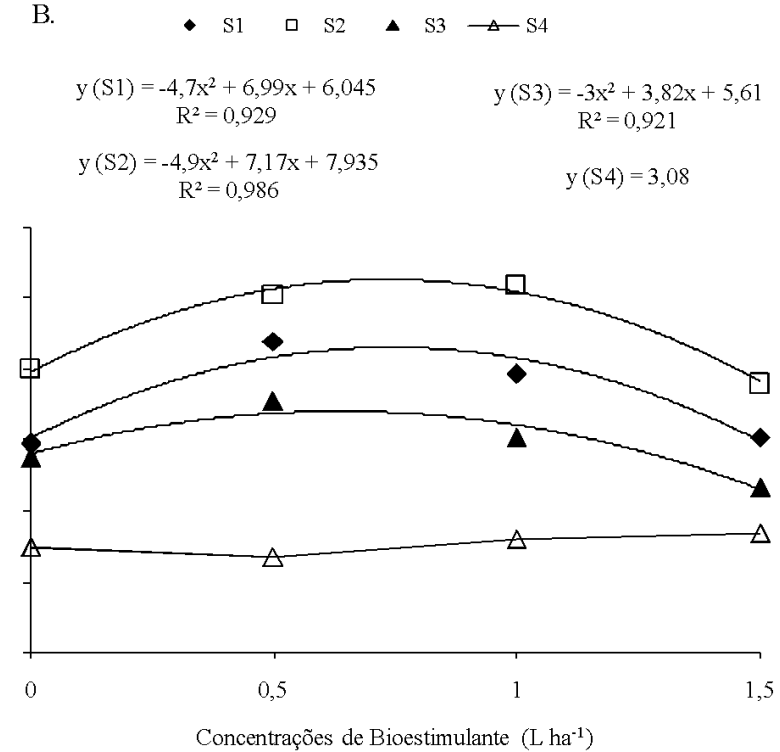

Figura 4. Produção de grãos em feijão caupi sob irrigação com águas salinas (A) e concentrações de bioestimulante (A) (B1-0; B2-0,5; B3-1,0 e B4-1,5 $\mathrm{L}_{\text {ha-1 }}$ de bioestimulante; S1-0,5; S2-2,0; S3-3,5 e S4-5,0 dS m-1)

visto que, de acordo com Ayers \& Westcot (1999), o feijão caupi é considerado uma espécie moderadamente tolerante à salinidade da água de irrigação apresentando salinidade limiar de 3,3 $\mathrm{dS} \mathrm{m}^{-1}$, apesar de tal tolerância variar em função de variações genéticas e condições ambientais. Efeito quadrático do aumento da salinidade sobre a produção de grãos do feijão caupi também foi observado por Silva et al. (2013).

Ainda na Figura 4A verifica-se que salinidade muito elevada provocou reduções na produção de grãos em todas as concentrações de bioestimulantes de maneira que os menores valores foram obtidos na maior salinidade $\left(0,5 \mathrm{dS} \mathrm{m}^{-1}\right)$, com 2,8 (B1); 2,7 (B2); 3,9 (B3) e 2,8 (B4) g por planta. Comparando as produções obtidas em cada concentração de bioestimulante a $5 \mathrm{dS} \mathrm{m}^{-1}$ com respectivas produções encontradas na menor salinidade, verificaram-se reduções de 54,8; 69,4; 51,9 e 56,0\%, para B1, B2, B3 e B4, respectivamente (Figura 4A). As reduções encontradas neste trabalho considerando os níveis extremos de salinidade $\left(0,5\right.$ e $\left.5,0 \mathrm{dS} \mathrm{m}^{-1}\right)$ são próximas às obtidas por Silva et al. (2013) que obtiveram redução total para essas mesmas salinidades, na ordem de $61,1 \%$.

Quanto ao efeito do bioestimulante sobre a produção de grãos verificaram-se respostas quadráticas para as plantas irrigadas com água de salinidade de 0,5; 2,0 e 3,5 dS m-1, nas quais se obtiveram produções máximas de 8,$6 ; 10,6 \mathrm{e}$ 6,8 g planta $^{-1}$, nas concentrações de 0,$74 ; 0,73$ e $0,64 \mathrm{~L} \mathrm{ha}^{-1}$, respectivamente (Figura $4 \mathrm{~B}$ ).

De acordo com Dourado Neto et al. (2014), a influência positiva dos tratamentos sobre os indicadores de rendimento de grãos pode ser devida à ação de reguladores vegetais na composição dos bioestimulantes fato passível de ser atribuído à presença de auxina, no sistema radicular das plantas; assim, a planta mais enraizada tem maior capacidade para absorver água e sais minerais disponíveis na solução do solo garantindo assim uma alocação mais rápida de substâncias para os drenos preferenciais da planta, como os grãos.

Aumentos na produção de grãos em resposta ao uso de bioestimulante também foram verificados por outros autores para o feijoeiro comum (Phaseolus vulgaris) em trabalhos desenvolvidos por Abrantes et al. (2011) e Dourado Neto et al. (2014); entretanto, outros autores (Ferreira et al., 2013; Almeida et al., 2014) concluíram que a produtividade do feijoeiro não é influenciada positivamente pelo uso de reguladores vegetais tanto no tratamento de sementes quanto em aplicação foliar.

Comparando as máximas produções com as obtidas na ausência de bioestimulante $\left(0,0 \mathrm{~L} \mathrm{ha}^{-1}\right)$, verificou-se que o aumento da salinidade reduziu a eficiência do bioestimulante de vez que houve maior aumento $(43 \%)$ na menor salinidade $\left(0,5 \mathrm{dS} \mathrm{m}^{-1}\right)$ reduzindo para $33 \%$ na salinidade $2,0 \mathrm{dS} \mathrm{m}^{-1} \mathrm{e}$ aumento de $22 \%$ na salinidade de $3,5 \mathrm{dS} \mathrm{m}^{-1}$ (Figura $4 \mathrm{~B}$ ). Já nas plantas submetidas ao maior nível salino não ocorreu efeito significativo do bioestimulante obtendo-se produção média de 3,08 g por planta.

Não foi observada resposta significativa à salinidade para o índice de colheita (IC), obtendo-se IC médio entre as salinidades de $77,3 \%$. Tal resultado é corroborado por outros estudos sobre o uso de água salina na cultura do feijão caupi em que não se constatou efeito da salinidade quanto a esta variável (Bezerra et al., 2010; Silva et al., 2013).

Na Figura 5 é apresentado o efeito das concentrações de bioestimulante sobre o índice de grãos (IG) verificando-se

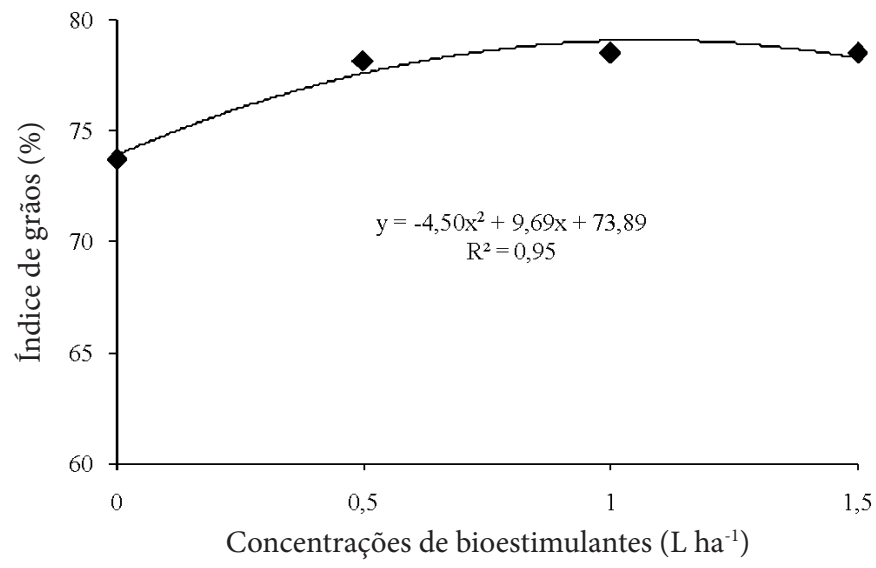

Figura 5. Índice de grãos em feijão caupi submetido a diferentes concentrações de bioestimulante 
que houve resposta quadrática nesta variável para o aumento nas concentrações de biorregulador, com maior IG ocorrendo nas concentrações de $1,1 \mathrm{~L} \mathrm{ha}^{-1}(79,1 \%)$, enquanto na ausência do bioestimulante $(73,9 \%)$, ocorrendo assim aumento de 5,2 unidades percentuais. Ainda na Figura 5 pode-se observar que, apesar de os dados terem sido ajustados ao modelo quadrático, houve pouca variação entre as concentrações de 0,5; 1,0 e 1,5 $\mathrm{L} \mathrm{ha}^{-1}$, obtendo-se valores de IG de 77,6; 79,1 e 78,3 , respectivamente.

Considerando que o IG representa a distribuição de fotoassimilados na vagem percebe-se que, independentemente da dosagem, o uso de bioestimulante favoreceu o maior enchimento dos grãos haja vista que mais de $77 \%$ de fotoassimilados foram drenados para o produto comercial (grãos). Silva \& Neves (2011) avaliaram o desempenho de 20 genótipos de feijão caupi em dois regimes hídricos (sequeiro e irrigação) e verificaram índice de grãos médio de 75,2\% (CV $=5,02 \%)$ para condições de sequeiro e 79,5\% (CV = 4,25\%), para condições de irrigação, valores próximos aos obtidos no presente trabalho indicando ainda que o manejo cultural pode alterar esta variável.

Fazendo uma análise geral, constatou-se que para a maioria das variáveis analisadas o efeito do bioestimulante pode ser reduzido ou até inibido por condições ambientais inadequadas; neste caso, pelo estresse salino. Tal fato reforça os resultados obtidos por Oliveira et al. (2013), os quais observaram que o uso do bioestimulante Stimulate não afetou o crescimento em plantas de feijão caupi submetidas ao estresse salino. Outros autores também constataram que o efeito do bioestimulante pode ser influenciado por fatores genéticos (Bertolin et al., 2010) e ambientais (Baldo et al., 2009; Ávila et al., 2010; Albrecht et al., 2012; Oliveira et al., 2013).

Diante dos resultados obtidos neste trabalho pode-se constatar que o uso do bioestimulante na cultura do feijão caupi é uma tecnologia promissora, desde que o produtor rural disponha de água de boa qualidade para a irrigação.

\section{Conclusões}

1. O uso do bioestimulante Stimulate com concentrações de 0,5 a $0,75 \mathrm{~L} \mathrm{ha}^{-1}$ proporciona aumento na produção de grãos de feijão caupi.

2. Concentrações elevadas de bioestimulante Stimulate associadas com o uso de águas salinas aumentaram os efeitos deletérios da salinidade sobre a produção de feijão caupi.

3. A prática da irrigação utilizando água com condutividade elétrica acima de $3,5 \mathrm{dS} \mathrm{m}^{-1}$ reduz ou inibe o efeito benéfico do bioestimulante sobre a cultura do feijão caupi.

\section{Literatura Citada}

Abrantes, F. L.; Sá, M. E.; Souza, L. C. D.; Silva, M. P.; Simidu, H. M.; Andreotti, M.; Buzetti, S.; Valério Filho, W. V.; Arruda, N. Uso de regulador de crescimento em cultivares de feijão de inverno. Pesquisa Agropecuária Tropical, v.41, p.148-154, 2011. http:// dx.doi.org/10.5216/pat.v41i2.8287
Albrecht, L. P.; Braccini, A. L.; Scapim, C. A.; Ávila, M. R.; Albrecht, A. J. P. Biorregulador na composição química e na produtividade de grãos de soja. Revista Ciência Agronômica, v.43, p.774-782, 2012. http://dx.doi.org/10.1590/S180666902012000400020

Almeida, A. Q.; Soratto, R. P.; Broetto, F.; Cataneo, A. C. Nodulação, aspectos bioquímicos, crescimento e produtividade do feijoeiro em função da aplicação de bioestimulante. Semina: Ciências Agrárias, v.35, p.77-88, 2014. http://dx.doi.org/10.5433/16790359.2014v35n $1 \mathrm{p} 77$

Assis Júnior, J. O.; Lacerda, C. F.; Silva, F. B.; Silva, F. L. B.; Bezerra, M. A.; Gheyi, H. R. Produtividade do feijão-decorda e acúmulo de sais no solo em função da fração de lixiviação e da salinidade da água de irrigação. Engenharia Agrícola, v.27, p.702-713, 2007. http://dx.doi.org/10.1590/ S0100-69162007000400013

Ávila, M. R.; Barizão, D. A. O.; Gomes, E. P.; Fedri, G.; Albrecht, L. P. Cultivo de feijoeiro no outono/inverno associado à aplicação de bioestimulante e adubo foliar na presença e ausência de irrigação. Scientia Agraria, v.11, p.221-230, 2010. http://dx.doi.org/10.5380/ rsa.v11i3.17230

Ayers, R. S.; Westcot, D. W. A qualidade da água na agricultura. Campina Grande: UFPB, 1999. 218p.

Baldo, R.; Scalon, S. P. Q.; Rosa, Y. B. C. J.; Mussury, R. M.; Betoni, R.; Barreto, W. S. Comportamento do algodoeiro cultivar Delta Opal sob estresse hídrico com e sem aplicação de bioestimulante. Ciência e Agrotecnologia, v.33, p.1804-1812, 2009. http://dx.doi. org/10.1590/S1413-70542009000700018

Bertolin, D. C.; Sá, M. E.; ARF, O.; Furlani Junior, E.; Colombo, A. S.; Carvalho, F. L. B. M. Aumento da produtividade de soja com a aplicação de bioestimulantes. Bragantia, v.69, p.339-347, 2010. http://dx.doi.org/10.1590/S0006-87052010000200011

Bezerra, A. K. P.; Lacerda, C. F.; Hernandez, F. F. F.; Silva, F. B.; Gheyi, H. R. Rotação cultural feijão caupi/milho utilizando-se águas de salinidades diferentes. Ciência Rural, v.40, p.1075-1082, 2010. http://dx.doi.org/10.1590/S0103-84782010000500012

Castro, P. R. C.; Vieira, E. L. Aplicações de reguladores vegetais na agricultura tropical. Guaíba: Livraria e Editora Agropecuária, 2001. 132p.

CONAB - Companhia Nacional de Abastecimento. Acompanhamento da safra brasileira de grãos, v.2 - Safra 2014/15, n.10 - Décimo levantamento, Brasília, p. 1-109, julho 2015.<http://www.conab.gov. br/conteudos.php?a=1252\&t=2\&Pagina_objcmsconteudos=2\#A_ objcmsconteudos>. 24 Jul 2015.

Dourado Neto, D.; Dário, G. J. A.; Barbieri, A. P. P.; Martin, T. N. Ação de bioestimulante no desempenho agronômico de milho e feijão. Bioscience Journal, v.30, p.371-379, 2014.

EMBRAPA - Empresa Brasileira de Pesquisa Agropecuária Centro Nacional de Pesquisa de Solos. Manual de métodos de análise de solos. 2.ed. Rio de Janeiro: Embrapa CNPS, 1997. 212p.

EMBRAPA - Empresa Brasileira de Pesquisa Agropecuária. Sistema brasileiro de classificação de solos. 2.ed. Rio de Janeiro: EMBRAPA, 2006. 306p.

Ferreira, M. M. R.; Arf, O.; Gittil, D. C.; Ferreira, L. H. Z.; Silva, J. C. Reguladores vegetais e nitrogênio em cobertura em feijoeiro de inverno no sistema plantio direto. Revista Agrarian, v.6, p.268280, 2013. 
Furtado, G. F.; Sousa Júnior, J. R.; Xavier, D. A.; Andrade, E. M. G.; Sousa, J. R. M. Pigmentos fotossintéticos e produção de feijão Vigna unguiculata L. Walp. sob salinidade e adubação nitrogenada. Revista Verde de Agroecologia e Desenvolvimento Sustentável, v.9, p.291-299, 2014.

Klahold, C. A.; Guimarães, V. F.; Echer, M. M.; Klahold, A.; Contiero, R. L.; Becker, A. Resposta da soja (Glycine max (L.) Merrill) à ação de bioestimulante. Acta Scientiarum. Agronomy, v.28, p.179-185, 2006. http://dx.doi.org/10.4025/actasciagron.v28i2.1032

Medeiros, J. F. de; Lisboa, R. A.; Oliveira, M.; Silva Júnior, M. J.; Alves, L. P. Caracterização das águas subterrâneas usadas para irrigação na área produtora de melão da chapada do apodi. Revista Brasileira de Engenharia Agrícola e Ambiental, v.7, p.469-472, 2003. http://dx.doi.org/10.1590/S1415-43662003000300010

Medeiros, J. F. de; Silva, M. C. C.; Sarmento, D. H. A.; Barros, A. D. Crescimento do meloeiro cultivado sob diferentes níveis de salinidade, com e sem cobertura do solo. Revista Brasileira de Engenharia Agrícola e Ambiental, v.11, p.248-255, 2007. http:// dx.doi.org/10.1590/S1415-43662007000300002
Oliveira, F. A.; Medeiros, J. F. de; Oliveira, M. K. T.; Souza, A. A. T.; Ferreira, J. A.; Souza, M. S. Interação entre salinidade e bioestimulante na cultura do feijão caupi. Revista Brasileira de Engenharia Agrícola e Ambiental, v.17, p.465-471, 2013. http:// dx.doi.org/10.1590/S1415-43662013000500001

Oliveira, G. A.; Araújo, F. W; Cruz, P. L. S; Silva, W. L. M.; Ferreira, G. B. Resposta do feijão-caupi as lâminas de irrigação e as doses de fósforo no cerrado de Roraima. Revista Ciência Agronômica, v.42, p.872882, 2011. http://dx.doi.org/10.1590/S1806-66902011000400008

Rhoades, J. P.; Kandiah, A.; Mashali, A. M. The use saline waters for crop production. Campina Grande: UFPB, 2000. 117p.

Silva, F. L. B.; Lacerda, C. F. de; Neves, A. L. R.; Sousa, G. G.; Sousa, C. H. C.; Ferreira, F. J. Irrigação com águas salinas e uso de biofertilizante bovino nas trocas gasosas e produtividade de feijãode-corda. Irriga, v.18, p.304-317, 2013. http://dx.doi.org/10.15809/ irriga.2013v18n2p304

Silva, J. A. L.; Neves, J. A. Produção de feijão-caupi semi-prostrado em cultivos de sequeiro e irrigado. Revista Brasileira de Ciências Agrárias, v.6, p.29-36, 2011. http://dx.doi.org/10.5039/agraria.v6ila748 